\title{
FRACTURE CRITERION FOR ICE USING A DISLOCATION MODEL
}

\author{
By V. R. PARAMESWARAN \\ (Division of Building Research, National Research Council of Canada, Ottawa, Ontario \\ K1A 0R6, Canada)
}

\begin{abstract}
The propensity for crack formation on basal and prismatic planes and twin nucleation on two pyramidal planes in hexagonal ice is examined on the basis of fracture theories and anisotropic elastic theories of dislocations. Calculations show that the ease of crack formation is almost the same in the basal and prismatic planes, whereas it is almost impossible to produce mechanical twinning in ice by stress alone.
\end{abstract}

RÉSUMÉ. Conditions de fracture de la glace d'après une théorie des dislocations. Sur la base des théories de la fracture et des théories élastiques anisotropiques des dislocations on examine les possibilites pour la formation de fissures sur les plans de base et sur les faces pyramidales ainsi que la nucleation des macles sur deux faces pyramidales dans de la glace hexagonale. Les calculs montrent que la formation de fissure est presque aussi facile sur le plan de base et sur les faces prismatiques, alors qu'il est presque impossible de produire des macles dans la glace par le seul exercice d'un effort mécanique.

ZUSAMMENFASSUNG. Ein Bruchkriterium für Eis, gewonnen aus einem Versetzungsmodell. Auf der Grundlage von Bruchtheorien und Theorien zur anisotropen elastischen Versetzung wird die Neigung zur Rissbildung an Grund- und prismatischen Flächen und zur Zwillingskernbildung an zwei pyramidischen Flächen in hexagonalem Eis untersucht. Berechnungen zeigen, dass sich Risse ebenso leicht in Grundflächen wie in prismatischen Flächen bilden können, dass es aber fast unmöglich ist, mechanische Zwillingsbildung im Eis allein durch Druckspannung zu erzeugen.

\section{INTRODUCTION}

To formulate the failure criterion of a solid it is important to know the elastic strain energy $E$ of the solid containing cracks and the crack extension force $G$, which is equal to the negative of the derivative of the elastic energy with respect to crack length. In considering stress fields due to cracks in fracture mechanics, it is customary to distinguish the three cases shown in Figure 1 (Bilby and Eshelby, 1968):

$$
\begin{array}{ll}
\begin{array}{l}
\text { Mode I crack: } \\
\text { (tensile crack) }
\end{array} & \sigma_{x y}=0, \sigma_{x x}=0, \sigma_{y y} \neq 0, \text { on the plane } y=0 . \\
\begin{array}{l}
\text { Mode II crack: } \\
\text { (shear crack) }
\end{array} & \sigma_{x x}=0, \sigma_{y y}=0, \sigma_{x y} \neq 0, \text { on } y=0 . \\
\begin{array}{l}
\text { Mode III crack: } \\
\text { (tearing type of crack) }
\end{array} & \sigma_{x z}=0, \sigma_{y z} \neq 0, \text { on } y=0 .
\end{array}
$$

The elastic stress field and the energy of such cracks in terms of externally applied stress fields have been derived by several workers: Stroh (1958) has formally treated the problem for a general anisotropic medium using the method of Fourier transforms and dual integral equations, and Barnett and Asaro (1972) have used the method of double-ended pile-up of continuously distributed, infinitesimal dislocations, to solve the problem of a slit-like crack in an arbitrarily anisotropic elastic medium under uniform stress. Yoo $(1979,1980)$ has used these solutions to calculate the elastic energy of slit cracks in hexagonal crystals and to develop a dislocation model for twinning and fracture in metals of hexagonal close-packed structure.

In this paper the above solutions are used for ice having a hexagonal structure to calculate the ratios of the critical stresses for crack initiation on the basal and prismatic planes, as well as the ratios of the surface energies associated with cracks. The ratios of the critical stresses for basal cleavage and $\{10 \overline{1} 2\}$ twin and for prismatic cleavage and $\{10 \overline{1} 1\}$ twin are also calculated. From these ratios a prediction is made of the tendency for twinning and cleavage in ice. 


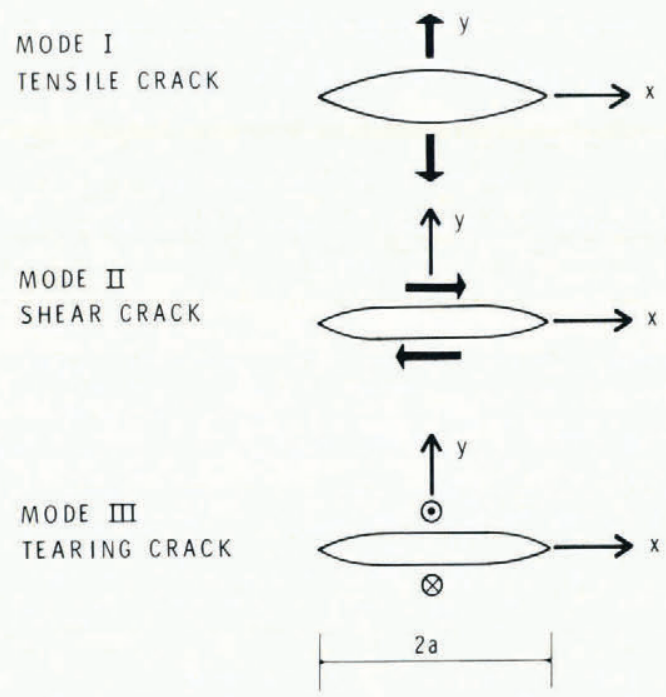

Fig. 1. The three modes of crack propagation in a solid.

\section{BACKGROUND OF THE CALCULATIONS}

Yoo $(1979,1980)$ derived the equations for critical stresses for crack and twin initiation from the Bilby and Eshelby (1968) theory. By considering a crack as a double-ended pile-up of dislocations, the critical stresses for formation of the three modes of cracks shown in Figure 1 are as follows (Yoo, 1979):

for a Mode I crack under a uniaxial stress $\sigma_{22}$ :

$$
\sigma_{22}^{\star}=\left(\frac{4 \gamma}{\pi a B_{22}}\right)^{1 / 2},
$$

for a Mode II crack under a shear stress $\sigma_{21}$ :

$$
\sigma_{21}^{\star}=\left(\frac{4 \gamma}{\pi a B_{11}}\right)^{1 / 2},
$$

and for a Mode III crack under a shear stress $\sigma_{23}$ :

$$
\sigma_{23}^{\star}=\left(\frac{4 \gamma}{\pi a B_{33}}\right)^{1 / 2} .
$$

The subscripts 1,2 , and 3 correspond to the cartesian coordinates $x, y$, and $z$. The elastic compliance factor $B_{i j}$ is the symmetrical second-rank tensor defined by Stroh (1958), depending on the elastic constants $C_{i j}$ and crack orientation; $i, j$ take any of the values 1,2 , and $3 ; 2 a$ is the length of the crack. The surface energy $\gamma$ associated with the crack plane $x_{2}=0$, is given by (Yoo, 1979)

$$
\gamma_{h k l}=\left(\frac{2}{\pi}\right)^{2}\left(C_{22}^{\prime} d\right)_{h k l}
$$

where $C_{22}^{\prime}$ is the transformed elastic stiffness constant with respect to the crack plane ( $\left.h k l\right)$ having interplanar spacing $d$. 
For an orthotropic medium (a solid with three mutually perpendicular planes of symmetry) $B_{i j} \mathrm{~s}$ are the inverse of the energy factors $K_{i j}$ for a dislocation, and expressions for these in terms of standard elastic constants have been obtained by Savin and others (1976). For a dislocation lying on the basal plane with Burgers vector $\boldsymbol{b}=\frac{1}{3}\langle 1 \overline{2} 10\rangle$, they show that

$$
\begin{gathered}
K_{22}=\frac{1}{B_{22}}=\left(\lambda^{2} C_{33}+C_{13}\right)\left\{\frac{C_{44}\left(\lambda^{2} C_{33}-C_{13}\right)}{C_{11}\left(\lambda^{2} C_{33}+C_{13}+2 C_{44}\right)}\right\}^{1 / 2}, \\
K_{11}=\frac{1}{B_{11}}=K_{22} \lambda^{2},
\end{gathered}
$$

and

$$
K_{33}=\frac{1}{B_{33}}=\left\{\frac{\left(C_{11}-C_{12}\right) C_{44}}{2}\right\}^{1 / 2},
$$

where

$$
\lambda^{2}=\left(\frac{C_{11}}{C_{33}}\right)^{1 / 2} .
$$

From Equation (4), the ratio of the surface energies associated with cracks in the basal and prismatic planes is given by $($ Yoo, 1979)

$$
\frac{\gamma_{\mathrm{b}}}{\gamma_{\mathrm{p}}}=\frac{1}{\alpha} \frac{c}{a} \frac{C_{33}}{C_{11}}
$$

where $\alpha=\sqrt{3}$ for $\{10 \overline{1} 0\}$ planes and 2 for $\{11 \overline{2} 0\}$ planes. $c$ and $a$ are the lattice parameters for the hexagonal lattice, in the present case of ice. Equations (1) to (9) can be used to give the ratio of the critical stress for crack extension in the basal and prismatic planes as (Yoo, 1979)

$$
\begin{gathered}
\left.\frac{\sigma_{\mathrm{b}}}{\sigma_{\mathrm{p}}}\right|_{\|}=\left(\frac{c}{\alpha a}\right)^{1 / 2} \frac{1}{\lambda^{3}}, \\
\left.\frac{\sigma_{\mathrm{b}}}{\sigma_{\mathrm{p}}}\right|_{\perp}=\left(\frac{c}{\alpha a}\right)^{1 / 2}\left(\frac{2 C_{33}\left(\lambda^{2} C_{33}+C_{13}\right)}{C_{11}^{2}-C_{12}^{2}}\right)^{1 / 2}\left(\frac{C_{44}\left(\lambda^{2} C_{33}-C_{13}\right)}{C_{11}\left(\lambda^{2} C_{33}+C_{13}+2 C_{44}\right)}\right)^{1 / 4} .
\end{gathered}
$$

The subscripts $\|$ and $\perp$ indicate whether crack extension occurs parallel or perpendicular to the $c$-axis.

To calculate the critical stress for twin nucleation, Yoo (1980) treats a micro-twin as a slit crack, for simplicity, neglecting the finite thickness of the twin and the welded boundary conditions for twin interfaces. Although far from rigorous, this treatment enables one to estimate the propensity for twin nucleation versus crack propagation. Two cases are considered: $(a)$ basal cleavage versus $\{10 \overline{1} 2\}$ twin, and $(b)$ prismatic cleavage versus $\{10 \overline{1} 1\}$ twin.

From Equation (1) the critical stress for crack extension on the basal plane can be written as

$$
\sigma_{\mathrm{c}}=\sigma_{22}^{\star}=\left(\frac{f_{\mathrm{c}}}{\pi a B_{22}}\right)^{1 / 2}
$$

where $f_{\mathrm{c}}$ is the total inelastic resistance to crack extension; this includes both the lattice resistance to dislocation motion and the surface energy associated with the crack forces. Considering a micro-twin as a Mode II slit crack, the condition for twin extension from the 
Bilby-Eshelby theory, is given by Yoo (1980) as

$$
\frac{f_{\mathrm{t}}}{\pi a} \leqslant B_{11}^{\prime}\left(\sigma_{12}^{\prime}\right)^{2}+B_{12}^{\prime} \sigma_{12}^{\prime} \sigma_{22}^{\prime}
$$

where $\sigma_{i j}^{\prime}$ denotes the stress components with respect to the twin axis $x_{i}^{\prime}$ inclined at angle $\theta$ with the original coordinate axis $x_{i}$, and $f_{\mathrm{t}}$ is the total inelastic resistance to twin extension.

For a uniaxial stress $\sigma_{22}$,

$$
\begin{aligned}
& \sigma_{12}^{\prime}=\sigma_{22} \sin \theta \cos \theta, \\
& \sigma_{22}^{\prime}=\sigma_{22} \cos ^{2} \theta .
\end{aligned}
$$

For a $\{10 \overline{1} 2\}\langle\overline{1} 011\rangle$ twin, which is the most common type in hexagonal close-packed crystals (see Fig. 2a),

$$
\begin{aligned}
& \sin \theta=\left(\frac{3 a^{2}}{4} /\left(\frac{3 a^{2}}{4}+\frac{c^{2}}{4}\right)\right)^{1 / 2}, \\
& \cos \theta=\left(\frac{c^{2}}{4} /\left(\frac{3 a^{2}}{4}+\frac{c^{2}}{4}\right)\right)^{1 / 2} .
\end{aligned}
$$

Using Equations (14) and (15) in (13), the critical stress $\sigma_{22}^{\star}$ for twin propagation is given by

$$
\sigma_{\mathrm{t}}=\sigma_{22}^{\star}=\left(\frac{f_{\mathrm{t}}}{\pi a}\right)^{1 / 2}\left(\frac{\left(3+\beta^{2}\right)^{2}}{\left(3 \beta^{2} B_{11}^{\prime}+\sqrt{3} \beta^{3} B_{12}^{\prime}\right)}\right)^{1 / 2}
$$

where $\beta=c / a$. For the isotropic case, $B_{12}^{\prime}=0$ and $B_{11}^{\prime}=B_{22}^{\prime}$; hence, from Equations (12) and (16), the ratio of the critical stresses for basal cleavage and $\{10 \overline{1} 2\}\langle\overline{1} 011\rangle$ twin is

$$
\frac{\sigma_{\mathrm{c}}}{\sigma_{\mathrm{t}}}=\frac{\sqrt{3} \beta}{\left(\beta^{2}+3\right)}\left(\frac{f_{\mathrm{c}}}{f_{\mathrm{t}}}\right)^{1 / 2} .
$$

Next, considering the ratio of the critical stresses for prismatic cleavage and a $\{10 \overline{1} 1\}$ twin, for a

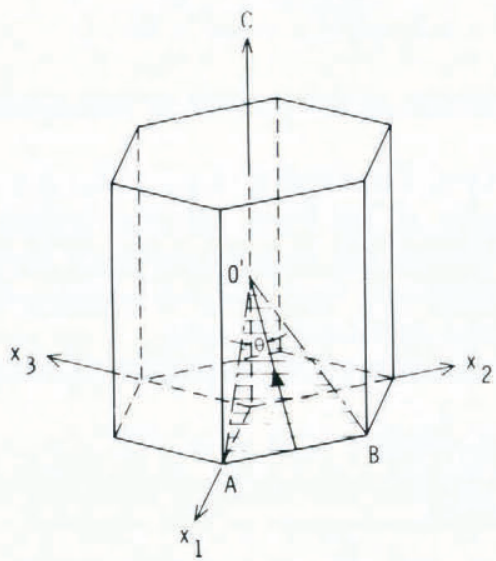

(a)

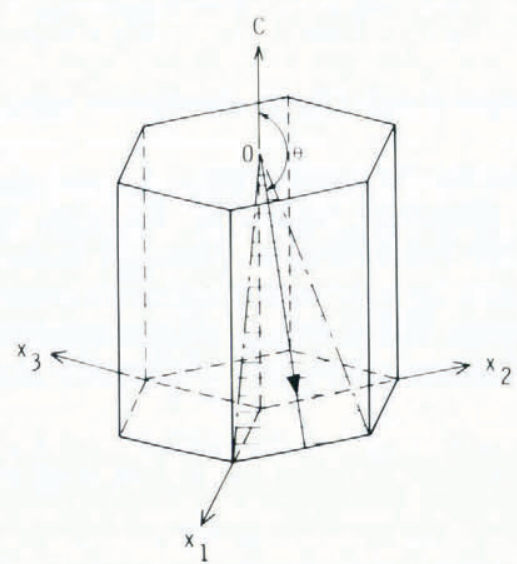

(b)

Fig. 2. Geometry of $a\{10 \overline{1} 2\}\langle\overline{1} 011\rangle \operatorname{twin}(a)$, and $a\{10 \overline{1} 1\}\langle 10 \overline{1} \overline{2}\rangle \operatorname{twin}(b)$. 
$\{10 \overline{1} 1\}\langle 10 \overline{1} \overline{2}\rangle$ twin (see Fig. 2b):

$$
\begin{aligned}
& \sin \theta=\left(\frac{3 a^{2}}{4} /\left(\frac{3 a^{2}}{4}+c^{2}\right)\right)^{1 / 2}, \\
& \cos \theta=-c /\left(\frac{3 a^{2}}{4}+c^{2}\right)^{1 / 2} .
\end{aligned}
$$

Using the conditions of Equations (18) and (14) in (13), the critical stress $\sigma_{22}^{\star}$ for twin propagation can be derived as (Yoo, 1980)

$$
\sigma_{\mathrm{t}}=\sigma_{22}^{\star}=\left(\frac{f_{\mathrm{t}}}{\pi a}\right)^{1 / 2}\left(\frac{\left(4 \beta^{2}+3\right)^{2}}{4 \beta^{2}\left(3 B_{11}^{\prime}-2 \sqrt{3} \beta B_{12}^{\prime}\right)}\right)^{1 / 2} .
$$

Analogous to Equation (12), the critical normal stress for extension of a Mode I crack on the $\{10 \overline{1} 0\}$ prism plane is

$$
\sigma_{\mathrm{c}}=\sigma_{11}^{\star}=\left(\frac{f_{\mathrm{c}}}{\pi a B_{11}^{\prime}}\right)^{1 / 2} .
$$

From Equations (19) and (20), and assuming $B_{12}^{\prime}=0$ for the isotropic case, the ratio of the critical stresses for prismatic cleavage and a $\{10 \overline{1} 1\}\langle 10 \overline{1} \overline{2}\rangle$ twin is;

$$
\frac{\sigma_{\mathrm{c}}}{\sigma_{\mathrm{t}}}=\frac{2 \sqrt{3} \beta}{\left(4 \beta^{2}+3\right)}\left(\frac{f_{\mathrm{c}}}{f_{\mathrm{t}}}\right)^{1 / 2} .
$$

Equations (9) to (11), (17), and (21) may now be used to calculate the surface energies of cracks in the basal and prism planes, and the ratios of the critical stresses for crack formation and twinning at various temperatures in ice. For a hexagonal lattice, the non-zero elastic constants are

$$
C_{11}=C_{22}, C_{12}, C_{13}=C_{23}, C_{33}, C_{44}=C_{55} \text {, and } C_{66}=\left(C_{11}-C_{12}\right) / 2 \text {. }
$$

The temperature dependence of these constants for ice has been given by Dantl (1968), and the temperature dependence of the lattice parameters $c$ and $a$ for ice by Lonsdale (1958).

\section{RESULTS AND DISCUSSIONS}

Values of the elastic constants $C_{i j}$ and the lattice parameters $c$ and $a$ calculated for various temperatures from Dantl's (1968) and Lonsdale's (1958) equations are shown in Table I. Figure $3 \mathrm{a}$ and $\mathrm{b}$ shows the variation of $C_{i j}, c, a$, and $c / a$ with temperature. Using these values in Equations (9) to (11), the ratios of surface energies $\left(\gamma_{b} / \gamma_{p}\right)$ and the critical stresses for crack formation $\left(\sigma_{\mathrm{b}} / \sigma_{\mathrm{p}}\right)$ in the basal and prismatic planes were calculated. Assuming $f_{\mathrm{c}}=f_{\mathrm{t}}\left(f_{\mathrm{c}}\right.$ and $f_{\mathrm{t}}$ are the lattice resistance to crack and twin propagation, and these include surface energies) in Equations (17) and (21), the ratios of the critical stresses for crack and twin propagation, namely $\sigma_{\mathrm{c}} / \sigma_{\mathrm{t}}$, were also calculated. All these values are shown in Table II. The value of $\gamma_{\mathrm{b}} / \gamma_{\mathrm{p}\{10 \overline{0}\}}$ is about 1.03 showing that the probability or ease of crack formation is almost the same in the basal and $\{10 \overline{1} 0\}$ prismatic planes. The ratio of the surface energies in the basal and the $\{11 \overline{2} 0\}$ planes, however, is about 0.89 , indicating that crack formation in the $\{11 \overline{2} 0\}$ plane is more difficult than that in the basal or $\{10 \overline{1} 0\}$ planes. The value of the ratio $\sigma_{b} / \sigma_{p}$ of critical stresses for crack extension in the basal and prismatic planes is almost equal to 1 for all temperatures, for cracks extending parallel or perpendicular to the $c$-axis.

These results suggest that, under a uniaxial stress, cracks could propagate in ice with equal ease, either along the basal or along the prism planes, although the probability of their 
TABLE I. VALUES OF ElASTIC CONSTANTS $C_{i j}$ (UNITS: $10^{3} \mathrm{MPa}$ ) AND LATTICE PARAMETERS $c$ AND $a$ (UNITS: $10^{-10} \mathrm{~m}$ )

$\begin{array}{rrrrrrrrr} & & & & & & & (77 \mathrm{~K}) & (4 \mathrm{~K}) \\ C_{11} & 13.0938 & 13.2787 & 13.4589 & 13.6344 & 13.8050 & 14.2108 & 15.7529 & 16.3452 \\ C_{12} & 6.6191 & 6.7464 & 6.8691 & 6.9871 & 7.1004 & 7.3630 & 8.2193 & 8.4034 \\ C_{13} & 5.7274 & 5.8327 & 5.9381 & 6.0434 & 6.1488 & 6.4122 & 7.6870 & 8.4561 \\ C_{44} & 2.8631 & 2.9052 & 2.9452 & 2.9832 & 3.0192 & 3.1001 & 3.3116 & 3.2946 \\ C_{33} & 14.3002 & 14.5171 & 14.7257 & 14.9261 & 15.1183 & 15.5626 & 16.9847 & 17.2585 \\ \left(C_{11}-C_{12}\right) / 2=C_{66} & 3.2374 & 3.2662 & 3.2949 & 3.3238 & 3.3523 & 3.4239 & 3.7668 & 3.9709 \\ \lambda^{2}=\left(C_{11} / C_{33}\right)^{1 / 2} & 0.9569 & 0.9564 & 0.9560 & 0.9558 & 0.9556 & 0.9556 & 0.9631 & 0.9732 \\ C_{12} & & & & & & & & \\ \nu=\frac{C_{12}}{2\left(C_{12}+C_{66}\right)} & 0.3358 & 0.3368 & 0.3379 & 0.3388 & 0.3396 & 0.3413 & 0.3429 & 0.3396 \\ c & & & & & & & & \\ a & 4.3639 & 7.3609 & 7.3581 & 7.3554 & 7.3528 & 7.3470 & 7.3307 & 7.3305 \\ c / a & 1.6289 & 4.5184 & 4.5162 & 4.5141 & 4.5121 & 4.5075 & 4.4928 & 4.4900 \\ & & & 1.6293 & 1.6294 & 1.6296 & 1.6300 & 1.6317 & 1.6326\end{array}$

occurrence on the basal and the $\{10 \overline{1} 0\}$ planes is slightly more than that along the $\{11 \overline{2} 0\}$ plane. (In this paper, crack propagation along planes at other angles to the $c$-axis, such as the pyramidal planes, has not been considered.) This coincides with observations made by Gold (1972), who carried out detailed and extensive studies on various aspects of cracking activity in ice. He found that in polycrystalline ice subjected to uniaxial compressive stress at temperatures between -5 and $-30^{\circ} \mathrm{C}$, about $25 \%$ of the observed cracks are along the grain boundaries, $42 \%$ in the basal plane, and $20 \%$ perpendicular to the basal plane; the rest were irregular. He also observed that the most probable direction of crack propagation is parallel to the compressive stress direction. Parameswaran and Jones (1975) tested single-crystal and polycrystalline ice at $-196^{\circ} \mathrm{C}(77 \mathrm{~K})$ under uniaxial compression. No particular orientation dependence was observed for crack propagation. The modes of failure were in general: $(a)$ axial cleavage with one or more

TABLE II. VALUES OF ENERGY FACTORS $K_{i j}=1 / B_{i j}$ (UNITS: $10^{3} \mathrm{MPa}$ ) AND RATIOS OF SURFACE ENERGY AND CRITICAL STRESSES FOR CRACK AND TWIN PROPAGATION

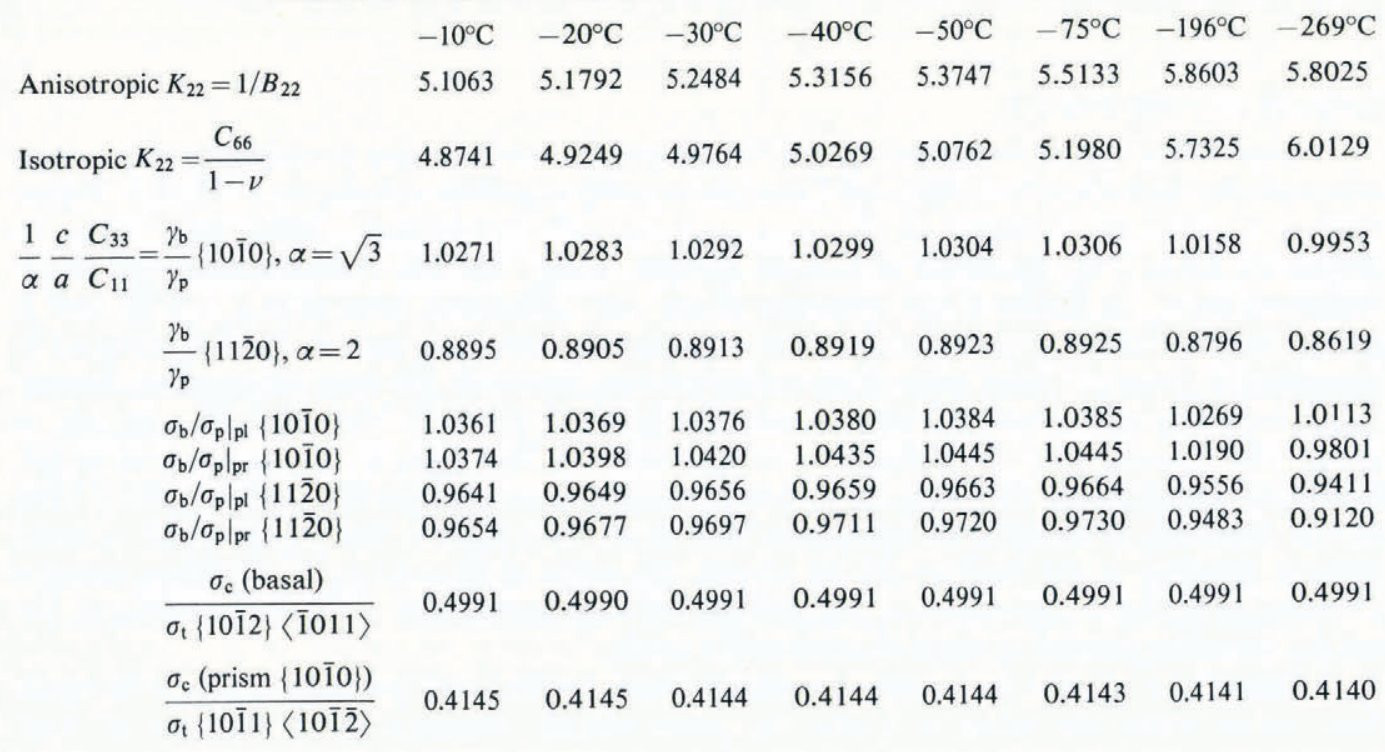




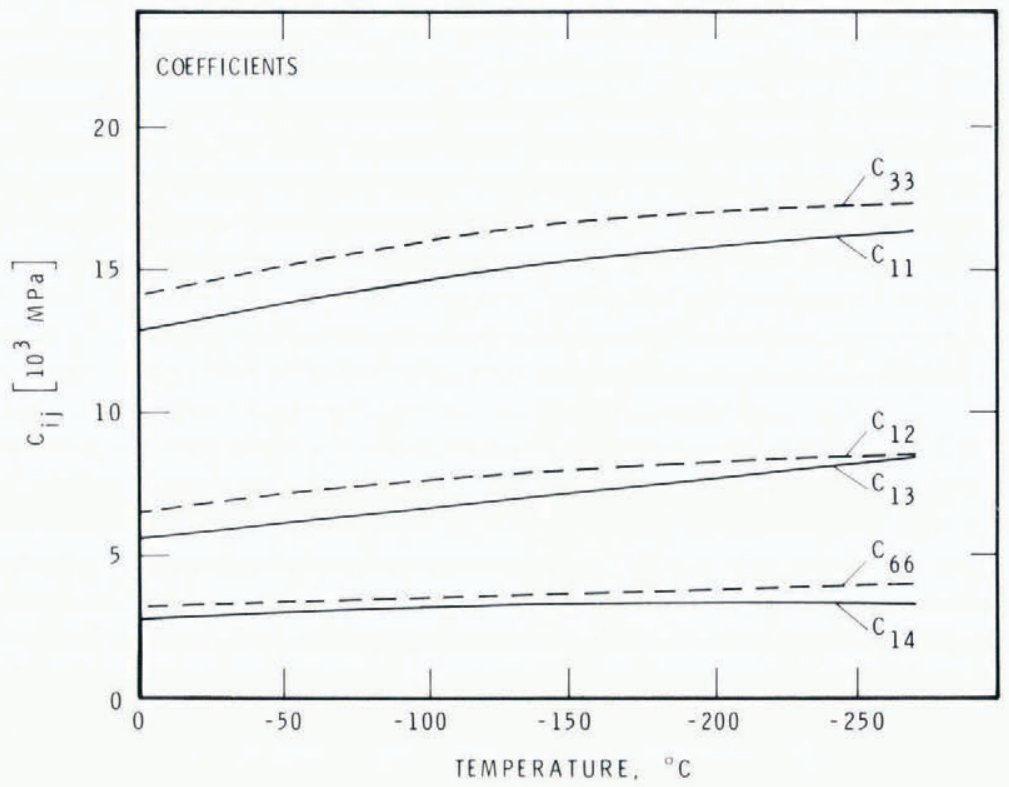

(a)

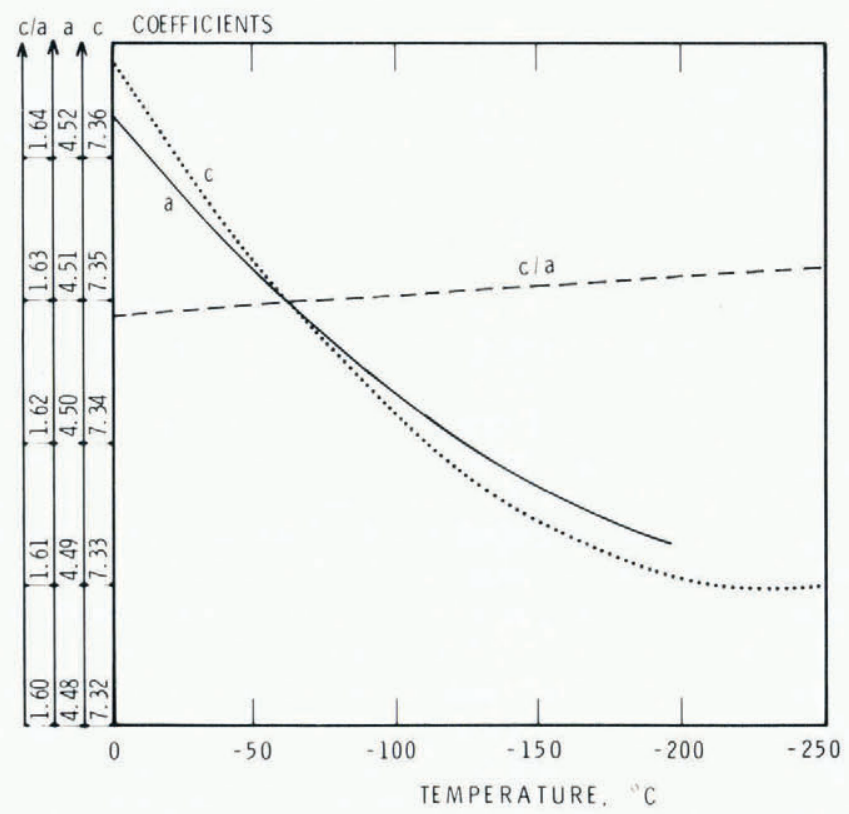

(b)

Fig. 3(a). Variation of elastic constants $C_{l}$ of ice with temperature. (b). Variation of lattice parameters $c$ and a with temperature.

major cracks splitting the sample along the loading direction, and $(b)$ cataclasis or general internal crumbling by formation of multiple cracks. The cracks did not follow any particular pattern or crystallographic plane. 
Considering the ratio $\sigma_{c} / \sigma_{t}$ of the critical stress for basal cleavage and $\{10 \overline{1} 2\}$ twin, or prismatic cleavage and $\{10 \overline{1} 1\}$ twin, it may be seen from Table II that $\sigma_{\mathrm{c}} / \sigma_{\mathrm{t}}$ has values of 0.5 and 0.41 respectively for the two cases. This shows that mechanical twinning is almost impossible in ice, because the critical stress required for twin initiation is twice that for cleavage crack propagation. This explains why no one so far has observed mechanical twinning in ice crystals, although several workers have studied the deformation behaviour of ice under various conditions. This does not preclude the existence of growth twins in ice. The peculiar shapes of snow crystals (grown under both natural and artificial conditions) observed by investigators such as Bentley and Humphreys (1931), Nakaya (1954), Kikuchi (1970), Kikuchi and Hogan (1976), and Yamashita (1971), have recently been explained as twins by Kobayashi and others (1976) on the basis of the generalized concept of coincidence-site lattice (CSL) theory. Kobayashi and Furukawa (1975) have also discussed the formation of the twelve-branched snow crystals observed by Doi (1832, 1840), Bentley and Humphreys (1931), and Nakaya (1954), in terms of rotation twinning.

From Equation (1) a theoretical value of the critical stress for crack extension can also be estimated. The critical stress intensity factor or strain-energy release rate for ice was found to depend on temperature and strain-rate, and under conditions of crack arrest associated with thermal shock Gold (1963) calculated the strain-energy release rate to be about $300 \mathrm{ergs} \mathrm{cm}^{-2}$. This means that

$$
2 \gamma+P=300 \operatorname{ergs~cm}^{-2}\left(3 \times 10^{-7} \mathrm{MN} \mathrm{m}^{-1}\right)
$$

or

$$
\gamma+P / 2=150 \text { ergs } \mathrm{cm}^{-2}\left(1.5 \times 10^{-7} \mathrm{MN} \mathrm{m}^{-1}\right)
$$

where $\gamma$ is again the surface energy and $P$ is the external work done. Gold (1972) uses a value for $\gamma=100 \mathrm{ergs} / \mathrm{cm}^{-2}\left(10^{-7} \mathrm{MN} \mathrm{m}^{-1}\right)$. One can also calculate the width $2 a$ of a critical crack by considering it as a pile-up of $n$ freely slipping edge dislocations (Bullough, 1964)

$$
2 a=\frac{\mu n^{2} b^{2}}{4 \pi(1-\nu) \gamma}
$$

where $\mu$ is the shear modulus ( $C_{66}$ for ice), and $b$ is the magnitude of the Burgers vector $\left(4.523 \times 10^{-10} \mathrm{~m}\right)$. The width of the critical crack depends on the choice of $n$, the number of dislocations in a pile-up. Bullough (1964) suggested a value of $n=300-700$ and Friedel (1964) suggested that $n$ could be $10^{2}$ to $10^{3}$. Using the values of $\mu\left(=C_{66}\right)$ and $\nu$ from Table I, and assuming $\gamma=100 \mathrm{ergs} \mathrm{cm}^{-2}\left(1 \times 10^{-7} \mathrm{MN} \mathrm{m}^{-1}\right), 2 a=0.23 \mathrm{~mm}$ at $-196^{\circ} \mathrm{C}$ and $0.2 \mathrm{~mm}$ at $-10^{\circ} \mathrm{C}$ for $n=500$, and $2 a=0.92 \mathrm{~mm}$ at $-196^{\circ} \mathrm{C}$ and $0.8 \mathrm{~mm}$ at $-10^{\circ} \mathrm{C}$ for $n=10^{3}$. These values are in good agreement with the experimentally observed value of $1 \mathrm{~mm}$ for the first large crack in ice subjected to a compressive stress (Gold, 1972).

Using these values of $a$ in Equation (1), the critical stress values calculated for crack formation at $-10^{\circ} \mathrm{C}$ were 2.49 and $1.25 \mathrm{MPa}$, respectively. These agree very well with the observed failure stresses for ice measured under tension, namely, 1 to $3 \mathrm{MPa}$ (Michel, 1978). The critical stress values calculated from Equation (1) for ice at $-196^{\circ} \mathrm{C}$, using $n=500$ and 1000 , were $2.52 \mathrm{MPa}$ and $1.26 \mathrm{MPa}$, respectively. These values are about one order of magnitude smaller than the fracture stresses observed by Parameswaran and Jones (1975)*. The values of failure stress under compression measured at $-196^{\circ} \mathrm{C}$ were in the range of 24 to $39 \mathrm{MPa}$ for natural as well as artificially grown single and polycrystalline ice. They observed, however, that the first crack appeared in the very early stages of deformation in the stress range $0.1-0.5 \mathrm{MPa}$.

\footnotetext{
* The numbers along the ordinates in figures 4, 5, and 9 of this reference are incorrect. The correct values of fracture stress in figures 4 and 5 vary between 10 and $100 \mathrm{MN} \mathrm{m}^{-2}$ (or $\mathrm{MPa}$ ), not 100 to $1000 \mathrm{MN} \mathrm{m}^{-2}$. In figure 9 the fracture stresses are in units of $\mathrm{MN} \mathrm{m}^{-2}$ (or $\left.\mathrm{MPa}\right)$, not $10^{4} \mathrm{MN} \mathrm{m}^{-2}$.)
} 


\section{CONCLUSION}

A dislocation model based on theories of fracture and anisotropic elasticity has been used to calculate the ratio of surface energies and the critical stresses for formation of cracks in the basal and prismatic planes of hexagonal ice. These calculations show that crack formation occurs with almost equal ease in both basal and prismatic planes. The calcuiations also show that it is almost impossible to produce mechanical twinning in ice by stress alone, because the critical stress for twin initiation is twice that required for cleavage crack formation, and this explains why no one so far has observed mechanical twins in ice.

\section{AcKNOWLEDGEMENT}

Sincere thanks are extended to Dr L. W. Gold for helpful discussions. This paper is a contribution from the Division of Building Research, National Research Council of Canada, and is published with the approval of the Director of the Division.

MS. received 8 January 1981 and in revised form 12 March 1981

\section{REFERENCES}

Barnett, D. M., and Asaro, R. J. 1972. The fracture mechanics of slit-like cracks in anisotropic elastic media. Journal of Mechanics and Physics of Solids, Vol. 20, No. 6, p. 353-66.

Bentley, W. A., and Humphreys, W. J. 1931. Snow crystals. New York, McGraw-Hill Book Co., Inc.

Bilby, B. A., and Eshelby, J. D. 1968. Dislocations and the theory of fracture. (In Liebowitz, H., ed. Fracture: an advanced treatise. New York, Academic Press, Vol. 1, p. 99-182.)

Bullough, R. 1964. The cracked dislocation under tension. Philosophical Magazine, Eighth Ser., Vol. 9, No. 102, p. $917-25$.

Dantl, G. 1968. Die elastischen Moduln von Eis-Einkristallen. Physik der kondensierten Materie, Bd. 7, Ht. 5, p. $390-97$.

Doi, T. 1832. Sekka zusetsu [Illustrations of snow crystals]. 2 vols. [Reprinted, with Doi (1840), in the series Nihon Kagakukoten Zensho (Tokyo, Asahi Shinbun-sha), [Vol.] 6, 1942, p. 629-84.]

Doi, T. 1840. Zoku sekka zusetsu [Supplementary volume of illustrations of snow crystals]. 2 vols. Friedel, J. 1964. Dislocations. English edition, based on a translation by L. F. Vassamillet. Oxford, etc., Pergamon
Press. Gold, L. W. 1963. Crack formation in ice plates by thermal shock. Canadian Journal of Physics, Vol. 41, No. 10,
p. 1712-28.

Gold, L. W. 1972. The failure process in columnar-grained ice. Canada. National Research Council. Division of Building Research. Technical Paper No. 369.

Kikuchi, K. 1970. Peculiar shapes of solid precipitation observed at Syowa Station, Antarctica. Journal of the Meteorological Society of Japan, Vol. 48, No. 3, p. 243-50.

Kikuchi, K., and Hogan, A. W. 1976. Snow crystal observations in summer season at Amundsen-Scott South Pole Station, Antarctica. Journal of the Faculty of Science, Hokkaido University, Ser. 7, Vol. 5, No. 1, p. 1-20.

Kobayashi, T., and Furukawa, Y. 1975. On twelve-branched snow crystals. Journal of Crystal Growth, Vol. 28, No. 1, p. $21-28$.

Kobayashi, T, and others. 1976. On twinned structures in snow crystals, [by] T. Kobayashi and Y. Furukawa and K. Kikuchi and H. Uyeda. Journal of Crystal Growth, Vol. 32, No. 2, p. 233-49. Lonsdale, K. 1958. The structure of ice. Proceedings of the Royal Society of London, Ser. A, Vol. 247, No. 1251,
p. 424-34.

Michel, B. 1978. The strength of polycrystalline ice. Canadian Journal of Civil Engineering, Vol. 5, No. 3, p. $285-300$.

Nakaya, U. 1954. Snow crystals. Cambridge, Mass., Harvard University Press. Parameswaran, V. R., and Jones, S. J. 1975. Brittle fracture of ice at 77 K. Journal of Glaciology, Vol. 14, No. 71,
p. 305-15.

Savin, M. M., and others. 1976. Energy factor of dislocations in hexagonal crystals, by M. M. Savin, V. M. Chernov, and A. M. Strokova. Physica Status Solidi (a), Vol. 35, No. 2, p. 747-54.

Stroh, A. N. 1958. Dislocations and cracks in anisotropic elasticity. Philosophical Magazine, Eighth Ser., Vol. 3, No. 30, p. 625-46.

Yamashita, A. 1971. Skeleton ice crystals of non-hexagonal shape grown in free fall. Journal of the Meteorological Society of Japan, Vol. 49, No. 3, p. 215-31. Yoo, M. H. 1979. The elastic energy of slit cracks in hexagonal crystals. Scripta Metallurgica, Vol. 13, No. 2,
p. 131-36.

Yoo, M. H. 1980. A dislocation model for twinning and fracture and its application to H.C.P metals. (In Haasen, P., and others, ed. Strength of metals and alloys. Proceedings of the Sth international conference, Aachen, Federal Republic of Germany, August 27-31, 1979. Edited by P. Haasen, V. Gerold, and G. Kostorz. Oxford, etc., Pergamon Press, Vol. 2, p. 825-30.) 